\title{
An Assessment of Provisions of Noncommunicable Disease Services on Health Promotion, Prevention and Control at Primary Health Care: A Case Study from Two Divisions of Bangladesh
}

\section{Sadia Sobhan Pinki ( $\nabla$ sadiasiyana@gmail.com )}

National Institute of Preventive and Social Medicine https://orcid.org/0000-0001-5620-0210

Iffan Nowroze Noor

National Institute of Preventive and Social Medicine

Bayzid Amin

National Institute of Preventive and Social Medicine

Md. Ziaul Islam

National Institute of Preventive and Social Medicine

Baizid Khoorshid Riaz

National Institute of Preventive and Social Medicine

\section{Research article}

Keywords: Noncommunicable disease, Bangladesh, Primary health care, Diabetes, Hypertension

Posted Date: December 8th, 2020

DOI: https://doi.org/10.21203/rs.3.rs-122532/v1

License: (c) (i) This work is licensed under a Creative Commons Attribution 4.0 International License.

Read Full License 


\section{Abstract}

\section{Background}

On its way to be counted as a middle-income country Bangladesh has a glorious story in fighting against communicable diseases; at present the health of the people are threatened by NCDs which is very alarming. This study was aimed to explore the insight of NCD services provided by primary health care centers (PHCCs) of Bangladesh.

\section{Methods}

A qualitative study was conducted in both urban $(n=10)$ and rural $(n=12)$ PHCCs. Those were chosen from the different clusters of divisions, based on High-income (Dhaka) and Low-income (Rangpur) between February to April 2020. In-depth interviews were carried out among 14 key informants and 22 health facility staff, and facility assessment was done through the checklist. Data were recorded, transcripted and checked to ensure the quality of the data. Triangulation of captured data was also done throughout the analysis process.

\section{Results}

The urban and rural primary health care centers (PHCCs) of Bangladesh are running under two different ministries. So, some fundamental differences are present in their characteristics. Irrespective of divisional income, most urban citizens do not even know about NCD services' availability in primary care settings. They visit facilities for their symptoms, mostly. Though rural patients generally visit the PHCCs, urban patients prefer the secondary or tertiary level facilities more. Facilities do have a lack of skilled staff in following standardized protocol mostly due to inadequate training. Moreover, lack of equipment, laboratory facility, and medicine also marked as obstacles. In this study, two rural facilities are piloting the PEN project, initiated by the government. Patients are getting better services at a low cost at these pilot facilities than other facilities. Except for the pilot facilities, the PEN protocol is mostly unknown to the other facility staff. Challenges and barriers in establishing standard practices for providing NCD services also differ among the facilities.

\section{Conclusions}

A more coordinated approach with evidence-based practice and the introduction of the PEN protocol in PHCCs can provide a better solution to fight against NCDs. Moreover, addressing the sustainability of the process is essential to ensure better health service. 


\section{Background}

Noncommunicable diseases (NCDs) kill 41 million people each year, equivalent to $71 \%$ of all deaths globally. Among those, 15 million dies between the ages of 30 and 69 years each year. Over $85 \%$ of these "premature" deaths occur in LMICs [1]. Bangladesh is experiencing rapid demographic and epidemiological transitions like the other low and middle-income countries (LMICs) [2-4]. There are 580 000 deaths from NCDs in Bangladesh each year, which is $67 \%$ of the country's total number [5]. The proportion of deaths due to NCDs in Bangladesh increased from 43.4\% in 2000 to $66.9 \%$ in 2015 [6].

Bangladesh's existing healthcare systems, which are mainly aimed at addressing communicable diseases, face a significant challenge with this increasing trend of NCDs [7, 8]. Several studies have shown that risk factors of NCDs, such as hypertension, dyslipidemia, physical inactivity, overweight, underweight, tobacco smoking, and low consumption of fruits and vegetables, are relatively common among Bangladeshi people living in both urban [9-11] and rural areas [10-12]. As the risk of developing NCDs increases, the impact of NCDs on individuals, families, communities, and the national economy is intolerable and expecting to be more serious [13-17]. Since most of the NCD patients can be primarily managed at primary health care centers (PHCCs), which are the first level of contact. Keeping all these in mind, the Government of Bangladesh (GoB) has taken some initiatives like setting up of 'NCD corners' at all Upazila (sub-district) health complexes (UHCs) [7] and piloting a community-based NCD management model [preferably hypertension (HTN) and diabetes mellitus (DM)] following WHO PEN (Package of Essential Noncommunicable Disease intervention) protocol in some selected sub-districts [5].

In Bangladesh, NCD prevention and management services have not yet been systematically available in all Upazilas and union levels, where the medical doctors are posted [18]. Moreover, there is a shortage of health worker density in our country, which does not meet the healthcare providers' ratio (1:3:5; per 10000 population) for providing primary health care [5]. To combat all the challenges, we need to integrate NCD service provisions at primary health care (PHC) to get the care they need, when they need it, in userfriendly ways, achieve the desired results and provide value for money $[19,20]$. This paper aimed to assess the performing capacity of PHCCs from two economically different divisions (high/low) in addressing NCD related health promotion along with prevention and control.

\section{Methods}

We conducted a qualitative study in urban and rural PHCCs of high and low-income divisions of Bangladesh from February to April 2020.

\section{Setting:}

Bangladesh currently has eight administrative divisions, which are divided into 64 districts (Zila), 490 sub-districts (Upazila), 4553 unions, and 12 city corporations [5]. 
In urban areas, urban primary health care centers (UPHCCs) are currently functioning under the Urban Primary Health Care Services Delivery Project (UPHCSDP). These are the responsibilities of the Local Government Engineering Department (LGED) of the Ministry of Local Government and Rural Development (MoLG \& RD). These UPHCCs cover city corporation or municipality area only. In rural areas, the rural PHC consists of UHC, USC, and CC, which are run under the Ministry of Health and Family Welfare (MOH\&FW). Health facility of Upazila is called Upazila Health Complex (UHC, total 424), in union 'Union Sub-Center' (USC, total 1312), and in community-level, it is Community Clinic (CC, total 13779). In this study, we randomly chose ten urban and 12 rural PHC facilities of both high-income Division (HID) and low-income division (LID), according to the 'Household Income and Expenditure Survey (HIES) 2016' (Table 1). The Dhaka division represented the HID as it got the highest average monthly household nominal income of BDT 19058 ( $\$ 244$ ) which exceeded the national average of BDT 15988 (\$205, $1 \$=78$ BDT in 2016), and Rangpur division represented the LID due to the least record of BDT 10547 (\$135) in 2016 [21].

\section{Study samples:}

This study included different study subjects to collect diverse, relevant data, considering PHCC locations (urban/rural) as well as health workforces. We invited 14 key informants and 26 PHC staff for their interview. Except four PHC staff, all other respondents participated in the study. Two of them denied due to their time constrain, one was not willing to talk regarding the issue, and the other one had to take leave from work. Finally we interviewed 14 key informants (KI) and 22 other PHC staff (Table 2 and T able 3). The Kls were center physicians for urban and the Upazila Health and Family Planning Officers (UH\&FPO), in-charge of the UHC for rural of both HID and LID. The sampling selection method is described in Figure 1 .

\section{Study tool:}

The study was conducted through an in-depth interview containing both open-ended and semi-structured questionnaires which was piloted prior to final data collection process. Question by question guideline was developed by the researchers for interview to ensure the quality of the data. The study also used a checklist to assess the facilities' readiness in providing NCD services in context to the aim of the study.

\section{Data collection:}

Main approaches used for data collection in this study were: (i) Desk reviews of some relevant national documents, including, e.g., Health Bulletin 2018, Population and housing census report 2011 Bangladesh, Household Income and Expenditure survey 2016; (ii) In-depth qualitative interviews of KIs and health facility staff; (iii) Researcher's observations together with brief semi-structured questionnaires and checklist for PHCC characteristics. Through informed written consent, participants were informed about goals and reasons to conduct the research. Prior to data collection privacy and confidentiality was ensured to create a favourable environment for the respondent. Face-to-face interviews were conducted at participants' working station within their working hour for about 45 mins to one hour by trained data enumerators. It was done in the local language (Bangla), and tape-recording and detailed notes were 
taken simultaneously with the permission of the interviewees. Among the researchers one person was responsible for two districts for mentoring the data collection process. They helped the enumerators of their designated districts to prevent bias or assumption that can influence the data collection. Again, they also helped in setting communication with respondents and data management. At the end of the day of the data collection period, the individual interview schedule was edited through checking and rechecking to see whether it was filled completely and consistently.

\section{Data analysis:}

After cleaning and corrections, data were analyzed using an inductive thematic analysis through comprehensive considerations of important codes or phrases or condensed meaning units immerged during the interviews. Coding was done by four data enumerators under direct supervision of two researchers experienced in qualitative research. Moreover, researchers provided a detail description of coding tree. The themes were derived from the data. All interview information was triangulated with related documents, other interviews, as well as researcher observations.

\section{Results}

\section{Background information of PHCCs in Bangladesh:}

The urban and rural PHCCs of Bangladesh are running under two different ministries. So, some basic differences in charecteristics of PHCCs are present between these two.(Table 4)

\section{Results of thematic analysis:}

\section{Theme 1: Magnitude of NCD burdens in Bangladesh is increasing}

The majority of the participants agreed that, in Bangladesh, the burden of NCDs and the number of patients experiencing NCD related problems are increasing in both urban and rural areas and is emerging as a public health challenge. The most common reasons for patient's visits to the facility were DM, hypertension (HTN), and sometimes respiratory problems. The other associated NCDs were mental health, road traffic accident, and injuries.

Some respondents said that, in most cases, patients visit health facilities with symptomatic complaints before they were diagnosed as NCD patients. As one participant noted:

"We face various difficulties to identify and treat patients with NCDs as people do not usually come to treat NCDs. Most of them come with general weakness, vertigo, nausea, blurred vision. Sometimes they even forget to mention symptoms that might help us identify NCD cases." KI-2

\section{Theme 2: Demand for staff training for better NCD services}

The study found that most health staff either in HID or LID could screen and diagnose DM and HTN. For other NCDs, they needed a physician's opinion. All of them could assess common risk factors like 
smoking, obesity, and physical inactivity and could also provide counseling to the patients on lifestyle modification. Almost all the urban and few rural PHCC physicians said that they did not receive any onthe-job training regarding NCD. According to their perception, more training on developing skills in diagnostic, treatment, and referral process could have increased their efficiency in delivering better services. . One urban physician quoted-

"No staff of this facility got training on NCD. I give treatment based on my working experience, previous knowledge, experience from previous patients, and by using a reference book. This facility is a bit far from the main town. So, patients come here first for primary management before going to secondary/ tertiary level hospitals. So, we need training on NCD to serve the patients more efficiently and effectively before referral."KI-11

\section{Theme 3: Limited supportive resources in PHC facilities without a special initiative project}

The Non-Communicable Disease Control (NCDC) program under the Directorate General of Health Services (DGHS) is currently piloting the NCD management model in some selected UHCs following the WHO PEN protocol both in HID and LID. In this study, we called them PEN pilot UHC. ${ }^{5}$ Among the selected facilities of this study, two of them were under this model (one in HID, one in LID). Participants of PEN pilot UHCs (physicians, nurses) got training from the NCDC program on PEN protocol and have guidelines and standardized protocol on DM and HTN. So, the staff could follow the protocols for diagnosis, treatment, referral, and follow-up of NCD patients. Moreover, these centers were getting regular supplies of medicine and medical equipment when compared to other PHCCs. So they are managing uncomplicated NCD patients more efficiently than the rest of the facilities. One UH\&FPO of HID stated -

"Generally, the patients receive basic NCD services, including consultation, basic investigation, treatment, and advice from us. Sometimes we get patients who are too serious, difficult to manage in UHC, and need an expert opinion. We refer those patients to the district hospital where the specialists are available." KI-8.

On the other hand, in non-pilot UHCs irrespective of HID or LID, skilled human resource, the supply of medicine and equipment was not adequate. They are not accustomed to using any guideline on HTN or DM management during serving the patients. So, the competency and capacity of the participants of those UHCs, were not compatible enough to provide the expected service. This study found that most USCs and CCs had little capacity to manage NCDs. So, they referred to all the NCD cases to UHC after screening. Some CHCPs got basic training on early detection for prevention and control of DM and HTN from the corresponding UHCs. They use referral slip for the referral process. One participant of LID mentioned about the treatment and referral process-

"This UHC is not under the PEN pilot project. There is no treatment guideline, and I did not receive any training from NCDC, DGHS, on PEN protocol. Moreover, there are a shortage of essential medicines, and sometimes patients have to buy medicine from outside. We also get NCD patients from the USCs and CCs. With all these obstacles, we try to give treatment to NCD patients and refer if not within our capacity." HS-18 


\section{Theme 4: Patients perspective in availing the NCD services at PHCs}

This study found that there were three important problems of NCD service provision at PHCs arising from the patient's perspective. First, many of the patients don't know about the availability of NCD service mainly at UPHCCs. One counsellor expressed the situation as-

"Urban PHCCs were mainly established to provide Maternal and Child health care. Many patients do not know about the availability of NCD services here. We have some regular outdoor patients of NCDs who are 'Red card' holders. They got full free treatment but very few in number." HS-4

Secondly, their preference in reporting to the tertiary level of hospitals directly both in HID and LID in an advantageous environment (short distance, well communication, higher wealth quintile, etc.). Another statement from health staff explains the existence of the issue-

"In this facility, we give treatment which is within our limit. Others got referred to Rangpur Medical College Hospital (RpMCH, Tertiary level hospital) by the physician. But the fact is, most of the NCD patients go to RpMCH/ specialist doctor chamber directly. Those who cannot afford that come to us for NCD treatment." HS-13

These two issues were also marked by one of the $\mathrm{KI}(04)$ while explaining the gaps and challenges in providing NCD services. Again, visit to have a follow up was found to be another point of ignorance by the patients, which was emphasized by one of the health staffs at PHCC from LID-

"This UHC is under the NCD pilot project. We can treat patients by following cost-effective interventions. We have sufficient essential medicines and laboratory facilities to treat mild to moderate cases. Patients get free medicine. Sometimes, we advise for admission. As it is a Government facility, people have to spend less money. Patients come for follow up as per advice, but all of them are not regular". HS-17

\section{Theme 5: Challenges and barriers in establishing standard practices for providing NCD services at PHCCs}

PEN disease protocol recommended some public health solutions which can decrease the risk of NCD through the life span, some interventions which can contribute to declining morbidity and mortality and the simultaneous use of risk prediction tools can identify the vulnerability of the people.

\section{i) NCD service through a lifespan approach-}

The data shows among the facilities, there was a similarity in their performances in providing solutions for the prevention and control of NCDs. All the facilities were found not performing the activities related to improvement in life skill education, restricting the marketing of food products high in salt/ sugar/ unhealthy fats, and improvement in availability and affordability of food. (see Additional file 1, Supplementary table 1)

According to the interviews, most participants concurred that counselling during Antenatal care (ANC) and Post-natal care (PNC) sessions, discussion during courtyard meeting and use of Information, 
Education and Communication (IEC) materials like posters/leaflet/dummy by the staff acted as enabling factors to implement public health solutions both in urban and rural areas. Among the others, advertisements on TV / social media, motivated school teachers in providing health education, and little doctor program were more pronounced.

On the other hand, lack of skills among staff, lack of awareness, and existence of social stigma among the people, patient overload at facilities were pointed as barriers by the participants. Another important aspect was staffs are not familiar with the use of any guidelines or protocol for NCD management during their service delivery process.

\section{ii) A core set of evidence-based interventions:}

According to the WHO PEN, these interventions are feasible for implementation in low-resource settings and can help reducing morbidity and mortality from major NCDs (here CVDs and DM) [22]. However, this study found that PHC staff, other than the physicians of both urban and rural areas, did not follow or even know about the WHO PEN. (see Additional file 2, Supplementary table 2)

Compared to pilot project facilities, health professionals of other facilities did not have a clear idea about the WHO PEN. All the facilities performed the activities as their routine work and mentioned counselling, court-yard meeting, and their residual knowledge as enabling factors. Among the barriers, lack of training, or refresher training, familiarity with guideline and skilled manpower were more pronounced. Piloted facilities also mentioned their obstacles. One of the staff from rural pilot UHCs said-

"Our UHC is under NCD pilot project, and some of us had training; so, we know about PEN recommendation by WHO. However, both physicians and nurses had this training, it is to some extent, difficult for nurses to perform these without supervision. In my opinion, lack of skilled manpower, along with failure to retain skilled staff and training of new staff, are the main barriers to implement the interventions." HS-17

\section{iii) Risk prediction tools:}

It is observed that risk prediction tools are not available in most of the facilities except the facilities under the pilot project (one from LID one from HID), and both of the facilities were in the rural area (Table 5). So that clearly shows the inadequate use of risk prediction tools in urban facilities. Moreover, the facilities using those tools also have to combat different situations to ensure the use of the tools. One of the health staff from pilot project UHC explained the challenge in using the tool-

"The physicians who had this training were transferred very recently. One nurse had this training but not that efficient. The trained doctors started to train up the other doctors but could not finish it. That is why currently, we do not use these tools. General patient overload is another cause."-HS-8

\section{Discussion}


Given the increasing burden of NCDs in the country, there has been a greater need for developing a feasible mechanism that addresses the problems of NCDs, meets the service delivery needs, and ensures the services are provided at the grass-root level with affordable cost [23]. This study provided an overview of the current status of provisions of NCD services in urban and rural PHCCs of high and low-income divisions.

Firstly, we identified a shortage of skilled manpower (both physicians and non-physicians) to manage NCDs both in urban and rural facilities of HID and LID. This finding is consistent with previous literature suggesting that healthcare workers working at a PHC level do need proper training to tackle NCDs at an early stage. For example, a study on health workers in Bangladesh said that trained healthcare providers play a vital role in the efforts of prevention and control of NCDs [24]. Some studies in sub-Saharan Africa have reported that major barriers to care and services for NCDs were poor knowledge and experience of front-line health workers $[25,26]$. Another study in Bangladesh by Rawal LB suggested that trained human resources are very important to address the NCD challenges [23].

Secondly, we found that there have been unequal supportive resources between those with and without government project initiative. Among the facilities with the pilot UHCs of the government, they had a standardized protocol for diagnosis, treatment, follow-up, or referral. On the other hand, the service of other facilities mostly depends on the care provider's residual knowledge, experience, and group discussion. A systematic review of NCD interventions in the Sub-Saharan Africa region gave priority on the use of the standardized protocol for diagnosis, treatment, monitoring, and referral to specialist care [27]. Most of the UHCs reported a poor follow up system and ignorance of the patients to have subsequent visits. A pilot testing on PEN in Bhutan reported that about $50 \%$ of patients with NCDs did not come for follow-up after three visits [28].

In addition, the study also found that, among the facilities, only pilot UHCs staff of rural PHCCs were familiar with WHO PEN, and they were getting the benefit of its' use. The health staff perceived that implementation of WHO PEN in PHCCs might provide a better scenario in preventing NCDs within a short time. Patients are getting better health services in a more efficient manner. It was also evident that patients with DM and HTN are completing their follow up visits timely than the previous. These findings corroborate with a pilot testing of WHO PEN in Bhutan. They got an improvement in blood pressure and diabetes control and reduction in CVD risk by the implementation of the PEN interventions in the primary healthcare setting of Bhutan [28]. Another study on the implementation of WHO PEN protocols in selected polyclinics of the Democratic People's Republic of Korea, reported that WHO PEN protocols related to cardiovascular disease and diabetes have improved risk management [29].

We faced some limitations. First, the study information that was based on participants' perceptions and experience might be prone to be biased under investigation. Nevertheless, we strictly employed qualitative methods. All data information had been triangulated with different sources of information, such as relevant documents, other interviews, and researcher's observations. Second, there were various types of $\mathrm{PHC}$ facilities with their specific contexts. This makes it difficult for discussion and limits some 
generalizability. Third, as the information system at a PHC level in Bangladesh is still developing, an absence of proper documentation and database management, mostly in urban settings, is another limitation. Lastly, the study was conducted during the period of the Covid-19 pandemic, this limited us for expanding more interviews and/or exploring more in-depth information from our health workers as they had to devote more time with combating the pandemic. This also prevented us from ensuring the saturation of data being collected.

\section{Conclusions}

The findings provide current insights about the situation and the challenges faced by PHC staff to manage NCDs in high and low-income divisions of Bangladesh. Most of the PHCCs are facing difficulties in providing recommended services for the prevention and treatment of NCDs. Additionally, unequal distribution of essential medical supplies, as well as skilled healthcare workers, would inhibit their capacity to address NCDs at a PHC level. However, increasing the supply of manpower, logistics, providing training can solve the problem for only a short period of time. Proper evidence-based and facility wise planning is required to overcome these obstacles in the long run. We must emphasize our planning that can ensure the sustainability of the process and standardization of the service to be followed.

\section{Abbreviations}

NCD: Noncommunicable Disease; PHC: Primary Health Care; PHCC: Primary Health care Center; LMIC: Low and Middle-Income Country; MOH\&FW: Ministry of Health and Family Welfare; MoLG\&RD: Ministry of Local Government and Rural Development; DGHS: Directorate General of Health Services; UHC: Upazila Health Complex; USC: Union Sub Center; CC: Community Clinic; HID: High Income Division; LID: Low Income Division; DM: Diabetes Mellitus; HTN: Hypertension; PEN: Package of Essential Noncommunicable diseases; ANC: Antenatal care; PNC: Post-natal care; WHO-World Health Organization; KI: Key Informant; HS: Health Staff; IEC material: Information, Education and Communication material.

\section{Declarations}

Ethics approval and consent to participate: To conduct the study, formal ethical approval was obtained from the Institutional Review Board (IRB) of the National Institute of Preventive and Social Medicine (NIPSOM), Dhaka, Bangladesh (Approval ID: NIPSOM/IRB/2020/13/1). Prior to interviews, participants were fully informed about the study objectives and how the obtained data will be used. As all interviews were audio-recorded, informed written consent was obtained from all the participants prior to the interview as well as for audio recording.

Consent for publication: Each and every participants were informed about this study and written consent was taken prior to the interview. 
Availability of data and materials: The data set used and/or analysed during the current study will be available from the corresponding author on reasonable request.

Competing interests: The authors declare that they have no competing interests.

Funding: The study received technical and financial supports by the International Health Policy Program (IHPP), Thailand, under the funding support of the Thailand Health Foundation However, the views expressed here are those of the authors, which are not necessarily reflecting the view and policy of the funding organizations.

Author's contributions: SSP: Protocol development, training, data analysis, manuscript preparation; INN: Protocol development, training, data analysis, manuscript preparation; KMBA: Protocol development, training; ZI: Protocol development, data analysis, manuscript preparation; BKR: Protocol development, training, data analysis, manuscript preparation. All authors read and approved the final manuscript.

Acknowledgments: We are thankful to all the participants of urban and rural PHCc facilities. Dr. Sanjida Islam, Program Officer, Dhaka south city corporation; Lt. Col. Md. Golam Mostofa, Deputy Chief Health Officer, Dhaka North city corporation; Md. Abdur Rahim Sumon, Project manager, Rangpur city corporation. We also thank the MPH graduates (Dr. Shahed, Dr. Ayesha, Dr. Mahfina, and Dr. Sadika) of NIPSOM for their support. We are grateful for the technical and funding support received from the International Health Policy Program (IHPP) and Thailand Health Foundation.

\section{Authors' information:}

1.Dr. Sadia Sobhan Pinki*: MBBS, MPH; Lecturer, Department of Public Health and Hospital Administration, National Institute of Preventive and Social Medicine (NIPSOM), Mohakhali, Dhaka, Bangladesh. Has been working in public health for last seven years.

2. Dr. Irfan Nowroze Noor: MBBS, MPH; Lecturer, Department of Maternal and Child Health, National Institute of Preventive and Social Medicine (NIPSOM), Mohakhali, Dhaka, Bangladesh. Previously worked in STEPS survey Bangladesh 2018.

3. Dr. K M Bayzid Amin: MBBS, MPH; Lecturer, Department of Public Health and Hospital Administration, National Institute of Preventive and Social Medicine (NIPSOM), Mohakhali, Dhaka, Bangladesh.

Previously worked in STEPS survey Bangladesh 2018.

4. Dr. Md. Ziaul Islam: MBBS, MPH, MSc, PhD; Professor and Head, Department of Community Medicine, National Institute of Preventive and Social Medicine (NIPSOM), Mohakhali, Dhaka, Bangladesh. Experienced in conducting qualitative study. Previously acted as Co-principal investigator in STEPS survey Bangladesh 2018.

5. Dr. Baizid Khoorshid Riaz: MBBS, MPH, PhD; Professor and Head, Department of Public Health and Hospital Administration and Director, National Institute of Preventive and Social Medicine (NIPSOM), 
Mohakhali, Dhaka, Bangladesh and Director of NIPSOM, Bangladesh. Experienced in conducting qualitative study. Previously acted as principal investigator in STEPS survey Bangladesh 2018.

\section{References}

1. Noncommunicable diseases https://www.who.int/en/news-room/factsheets/detail/noncommunicable-diseases Accessed 12 January 2020.

2. Statistics B. Population and housing census 2011. Dhaka: BBS 2012, 4.

3. Organization WH: Global status report on noncommunicable diseases 2014: World Health Organization; 2014.

4. Nations U: World Population Ageing 2015 (ST/ESA/SER. A/390). In.: Department of Economic and Social Affairs, Population Division New York, NY; 2015.

5. Directorate General of Health Services. Health Bulletin. In.; 2018.

6. Cause of death, by noncommunicable diseases (\% of total) https://data.worldbank.org/indicator/SH.DTH.NCOM.ZS Accesed 5 February 2020.

7. Alam D, Robinson H, Kanungo A, Hossain MD, Hassan M. Health Systems Preparedness for responding to the growing burden of noncommunicable disease-a case study of Bangladesh. Health Policy \& Health Finance knowledge Hub The Nossal Institute for Global Health The University of Melbourne 2013:1-25.

8. ZAMAN MM, NIEVERAS O, TALUKDER KABIRH. HT, BHUIYAN MR: CURRENT HEALTH SYSTEM SCENARIO FOR ADDRESSING NONCOMMUNICABLE DISEASES IN BANGLADESH.

Noncommunicable Diseases in Bangladesh:43.

9. Rawal LB, Biswas T, Khandker NN, Saha SR, Bidat Chowdhury MM, Khan ANS, Chowdhury EH, Renzaho A. Noncommunicable disease (NCD) risk factors and diabetes among adults living in slum areas of Dhaka, Bangladesh. PLoS One. 2017;12(10):e0184967.

10. Khalequzzaman M, Chiang C, Choudhury SR, Yatsuya H, Al-Mamun MA, Al-Shoaibi AAA, Hirakawa Y, Hoque BA, Islam SS, Matsuyama A. Prevalence of noncommunicable disease risk factors among poor shantytown residents in Dhaka, Bangladesh: a community-based cross-sectional survey. BMJ open. 2017;7(11):e014710.

11. Khandker NN, Biswas T, Khan ANS, Hasib E, Rawal LB. Socio-demographic characteristics and tobacco use among the adults in urban slums of Dhaka, Bangladesh. Tobacco Induced Diseases. 2017;15(1):26.

12. Biswas T, Garnett SP, Pervin S, Rawal LB. The prevalence of underweight, overweight and obesity in Bangladeshi adults: Data from a national survey. PloS one. 2017;12(5):e0177395.

13. Biswas T, Islam MS, Linton N, Rawal LB. Socio-economic inequality of chronic noncommunicable diseases in Bangladesh. PloS one. 2016;11(11):e0167140.

14. Beaglehole R, Bonita R, Alleyne G, Horton R, Li L, Lincoln P, Mbanya JC, McKee M, Moodie R, Nishtar S. UN high-level meeting on noncommunicable diseases: addressing four questions. The Lancet. 
2011;378(9789):449-55.

15. Rawal LB, Kanda K, Mahumud RA, Joshi D, Mehata S, Shrestha N, Poudel P, Karki S, Renzaho A: Prevalence of underweight, overweight and obesity and their associated risk factors in Nepalese adults: data from a Nationwide Survey, 2016. PloS one 2018, 13(11):e0205912.

16. Biswas T, Islam A, Islam MS, Pervin S, Rawal LB. Overweight and obesity among children and adolescents in Bangladesh: a systematic review and meta-analysis. Public Health. 2017;142:94101.

17. Sarker M, Hossain M, Rawal L: Epidemiology of noncommunicable diseases in Bangladesh: Bangladesh Health Watch Report 2016. Noncommunicable diseases in Bangladesh current scenario and future directions Dhaka: James P Grant School of Public Health BRAC University 2016:07-18.

18. Zaman M, Ullah A, Bhuiyan M, Karim M. Moniruzzaman and Rahman SMA. Noncommunicable Disease Prevention and Control Situation in a Primary. Health Care Setting of Bangladesh: Design Baseline Findings of an Intervention Chronic Dis Int. 2016;3(1):1021.

19. Organization WH. Integrated health services- What and why?. In.; 2008, May 1.

20. Tapela NM, Tshisimogo G, Shatera BP, Letsatsi V, Gaborone M, Madidimalo T, Ovberedjo M, Jibril HB, Tsima B, Nkomazana O. Integrating noncommunicable disease services into primary health care, Botswana. Bull World Health Organ. 2019;97(2):142.

21. Bangladesh Bureau of Statistics (BBS). Final Report of Household Income and Expenditure Survey (HIES). In.; 2016.

22. Organization WH: Package of essential noncommunicable (PEN) disease interventions for primary health care in low-resource settings. 2010.

23. Rawal LB, Kanda K, Biswas T, Tanim MI, Poudel P, Renzaho AM, Abdullah AS, Islam SMS, Ahmed SM. Noncommunicable disease (NCD) corners in public sector health facilities in Bangladesh: a qualitative study assessing challenges and opportunities for improving NCD services at the primary healthcare level. BMJ open. 2019;9(10):e029562.

24. Organization WH. Use of community health workers to manage and prevent noncommunicable diseases: policy options based on the findings of the COACH study. 2018.

25. Islam SMS, Purnat TD, Phuong NTA, Mwingira U, Schacht K, Fröschl G: Noncommunicable Diseases (NCDs) in developing countries: a symposium report. Globalization and health 2014, 10(1):1-8.

26. Rawal LB, Joarder T, Islam SMS, Uddin A, Ahmed SM. Developing effective policy strategies to retain health workers in rural Bangladesh: a policy analysis. Human resources for health. 2015;13(1):36.

27. Kane J, Landes M, Carroll C, Nolen A, Sodhi S. A systematic review of primary care models for noncommunicable disease interventions in sub-Saharan Africa. BMC Fam Pract. 2017;18(1):46.

28. Wangchuk D, Virdi NK, Garg R, Mendis S, Nair N, Wangchuk D, Kumar R. Package of essential noncommunicable disease (PEN) interventions in primary healthcare settings of Bhutan: a performance assessment study. WHO South-East Asia journal of public health. 2014;3(2):154-60. 
29. Hyon CS, Nam KY, Sun HC, Garg R, Shrestha SM, Ok KU, Kumar R. Package of essential noncommunicable disease (PEN) interventions in primary healthcare settings in the Democratic People's Republic of Korea: a feasibility study. WHO South-East Asia journal of public health. 2017;6(2):69-73.

\section{Tables}

Table 1: Distribution of selected facilities ( urban and rural)

\begin{tabular}{|c|c|c|c|c|}
\hline $\begin{array}{l}\text { Distribution of facilities according } \\
\text { to income and settings }\end{array}$ & $\begin{array}{l}\text { Name of } \\
\text { the facility }\end{array}$ & $\begin{array}{l}\text { Number of } \\
\text { facilities } \\
\text { Established }\end{array}$ & $\begin{array}{l}\text { Selected for } \\
\text { data collection }\end{array}$ & $\begin{array}{l}\text { Final } \\
\text { Number of } \\
\text { facilities }\end{array}$ \\
\hline \multirow[t]{6}{*}{ HIR } & $\mathrm{UHC}$ & 11 & 02 & 02 \\
\hline & & & $\begin{array}{l}\text { (Dhamrai \& } \\
\text { Louhajang) }\end{array}$ & \\
\hline & USC & $\begin{array}{l}07 \\
\text { (Dhamrai) + }\end{array}$ & $1+1=2$ & 02 \\
\hline & & $\begin{array}{l}04 \\
\text { (Louhajang) }\end{array}$ & & \\
\hline & $\mathrm{CC}$ & $\begin{array}{l}48 \\
\text { (Dhamrai) }+\end{array}$ & $1+1=2$ & 02 \\
\hline & & $\begin{array}{l}18 \\
\text { (Lohajang) }\end{array}$ & & \\
\hline \multirow[t]{6}{*}{ LIR } & $\mathrm{UHC}$ & 17 & 02 & 02 \\
\hline & & & $\begin{array}{l}\text { (Taraganj \& } \\
\text { Ulipur) }\end{array}$ & \\
\hline & USC & $\begin{array}{l}\text { 02(Taraganj) } \\
+\end{array}$ & $1+1=2$ & 02 \\
\hline & & 01 (Ulipur) & & \\
\hline & $\mathrm{CC}$ & $\begin{array}{l}15 \\
\text { (Taraganj) }+\end{array}$ & $1=1=2$ & 02 \\
\hline & & 56 (Ulipur) & & \\
\hline HIU & UPHCC & 55 & 06 & 06 \\
\hline LIU* & UPHCC & 06 & 06 & 04 ** \\
\hline Total= & & & 24 & 22 \\
\hline
\end{tabular}

Note: HIR= High Income Rural, LIR= Low Income Rural, HIU= High Income Urban, LIU= Low Income Urban; UHC-Upazila Health Complex, USC-Union Sub Center, CC-Community Clinic, UPHCC-Urban Primary Health 
Care Center, ${ }^{*}=$ All the facilities were included at first, the rest of the facilities were selected randomly. $* *=$ Due to non-functionality, two facilities were excluded.

\section{Table 2: List of interviewees [Key Informant (KI)]}




\begin{tabular}{|c|c|c|c|c|}
\hline Code & Workplace & $\begin{array}{l}\text { Number } \\
\text { of Kls }\end{array}$ & $\begin{array}{l}\text { Work } \\
\text { position }\end{array}$ & $\begin{array}{l}\text { Roles and/or involvement of NCD services at } \\
\text { PHCC }\end{array}$ \\
\hline \multirow[t]{7}{*}{ Kl:1-6 } & UPHCC (HID) & \multirow[t]{7}{*}{6} & \multirow{7}{*}{$\begin{array}{l}\text { Physician } \\
\text { and Clinic } \\
\text { manager }\end{array}$} & \multirow{7}{*}{$\begin{array}{l}\text { Treatment of uncomplicated NCD patients, } \\
\text { referral of complicated NCD patients, follow-up, } \\
\text { reporting to a higher authority. }\end{array}$} \\
\hline & $\begin{array}{l}\text { Aga Sadek } \\
\text { Road, Bongsal, } \\
\text { Dhaka(KI-1) }\end{array}$ & & & \\
\hline & $\begin{array}{l}\text { South } \\
\text { Jatrabari (KI-2) }\end{array}$ & & & \\
\hline & $\begin{array}{l}\text { South Goran } \\
(\mathrm{KI}-3)\end{array}$ & & & \\
\hline & $\begin{array}{l}\text { Amtoli, } \\
\text { Mohakhali (KI- } \\
\text { 4) }\end{array}$ & & & \\
\hline & $\begin{array}{l}\text { North Kafrul } \\
(\mathrm{KI}-5)\end{array}$ & & & \\
\hline & $\begin{array}{l}\text { Sultanganj, } \\
\text { Rayerbazar (KI- } \\
\text { 6) }\end{array}$ & & & \\
\hline \multirow[t]{3}{*}{$\mathrm{KI}: 7-8$} & UHC (HID) & \multirow[t]{3}{*}{2} & \multirow[t]{3}{*}{ UH \& FPO } & \multirow[t]{3}{*}{ Overall administrative management. } \\
\hline & $\begin{array}{l}\text { Dhamrai } \\
\text { UHC, Dhaka (KI- } \\
\text { 7) }\end{array}$ & & & \\
\hline & $\begin{array}{l}\text { Louhajang } \\
\text { UHC, } \\
\text { Munshiganj (KI- } \\
\text { 8) }\end{array}$ & & & \\
\hline \multirow{5}{*}{$\begin{array}{l}\mathrm{Kl}: 9- \\
12\end{array}$} & UPHCC (LID) & \multirow[t]{5}{*}{4} & \multirow[t]{5}{*}{ Physician } & \multirow{5}{*}{$\begin{array}{l}\text { Treatment of uncomplicated NCD pts, referral } \\
\text { of complicated NCD patients, follow-up, } \\
\text { reporting to a higher authority. }\end{array}$} \\
\hline & $\begin{array}{l}\text { Ershadnagar, } \\
\text { Rangpur (KI-9) }\end{array}$ & & & \\
\hline & $\begin{array}{l}\text { New } \\
\text { Jummapara } \\
(\mathrm{KI}-10)\end{array}$ & & & \\
\hline & $\begin{array}{l}\text { Sammanipur } \\
\text { (KI-11) }\end{array}$ & & & \\
\hline & $\begin{array}{l}\text { Sathmatha } \\
\text { (KI-12) }\end{array}$ & & & \\
\hline \multirow{2}{*}{$\begin{array}{l}\text { Kl:13- } \\
14\end{array}$} & UHC (LID) & \multirow[t]{2}{*}{2} & \multirow[t]{2}{*}{ UH \& FPO } & \multirow[t]{2}{*}{ Overall administrative management. } \\
\hline & $\begin{array}{l}\text { Taraganj } \\
\text { UHC, Rangpur } \\
\text { (KI-13) }\end{array}$ & & & \\
\hline
\end{tabular}


$\diamond$ Ulipur UHC,

Kurigram (KI-

14)

Note: UPHCC-Urban Primary Health Care Center, HID- High Income Division, LID- Low Income Division, UHC-Upazila Health Complex, UH\&FPO- Upazila Health and Family Welfare Officer.

Table 3: List of interviewees [(Health facility staff (HS)] 


\begin{tabular}{|c|c|c|c|c|}
\hline Code & Workplace & $\begin{array}{l}\text { Number } \\
\text { of HS }\end{array}$ & $\begin{array}{l}\text { Work } \\
\text { position }\end{array}$ & $\begin{array}{l}\text { Roles and/or involvement of NCD } \\
\text { services at PHCC }\end{array}$ \\
\hline \multirow[t]{7}{*}{ HS:1-6 } & UPHCC (HID) & \multirow[t]{7}{*}{06} & \multirow[t]{7}{*}{ Paramedics } & \multirow{7}{*}{$\begin{array}{l}\text { Assist the physician in providing } \\
\text { treatment, provides advice and } \\
\text { facilitate treatment and referral } \\
\text { process where applicable }\end{array}$} \\
\hline & $\begin{array}{l}\text { Aga Sadek Road, } \\
\text { Dhaka (HS-1) }\end{array}$ & & & \\
\hline & $\begin{array}{l}\text { South Jatrabari } \\
\text { (HS-2) }\end{array}$ & & & \\
\hline & 3) South Goran (HS- & & & \\
\hline & $\begin{array}{l}\text { Amtoli, Mohakhali } \\
\text { (HS-4) }\end{array}$ & & & \\
\hline & $\downarrow$ North Kafrul (HS-5) & & & \\
\hline & $\begin{array}{l}\text { Sultanganj, } \\
\text { Rayerbazar (HS-6) }\end{array}$ & & & \\
\hline \multirow[t]{3}{*}{ HS:7-8 } & $\mathrm{UHC}(\mathrm{HID})$ & \multirow[t]{3}{*}{02} & \multirow[t]{3}{*}{ IMO/RMO } & \multirow[t]{3}{*}{ Treatment, referral, and follow-up } \\
\hline & $\begin{array}{l}\text { Dhamrai, Dhaka } \\
\text { (HS-7) }\end{array}$ & & & \\
\hline & $\begin{array}{l}\text { Louhajang, } \\
\text { Munshiganj, Dhaka } \\
\text { (HS-8) }\end{array}$ & & & \\
\hline \multirow{4}{*}{$\begin{array}{l}\text { HS:9- } \\
10\end{array}$} & USC & \multirow[t]{4}{*}{02} & \multirow[t]{4}{*}{ SACMO } & \multirow[t]{4}{*}{ Counselling, referral } \\
\hline & $\begin{array}{l}\text { Mahishashi, } \\
\text { Dhamrai, Dhaka }\end{array}$ & & & \\
\hline & (HS-9) & & & \\
\hline & $\begin{array}{l}\text { Kanakshar, } \\
\text { Munshiganj, Dhaka } \\
\text { (HS-10) }\end{array}$ & & & \\
\hline \multirow{3}{*}{$\begin{array}{l}\text { HS:11- } \\
12\end{array}$} & $\mathrm{CC}$ & \multirow[t]{3}{*}{02} & \multirow[t]{3}{*}{$\mathrm{CHCP}$} & \multirow[t]{3}{*}{ Counselling, referral } \\
\hline & $\begin{array}{l}\text { Hazipur, Dhamrai, } \\
\text { Dhaka (HS-11) }\end{array}$ & & & \\
\hline & $\begin{array}{l}\text { Shingerhati, } \\
\text { Munshiganj, Dhaka } \\
\text { (HS-12) }\end{array}$ & & & \\
\hline \multirow{3}{*}{$\begin{array}{l}\text { HS:13- } \\
16\end{array}$} & UPHCC (LID) & \multirow[t]{3}{*}{04} & \multirow[t]{3}{*}{ Counsellor } & \multirow{3}{*}{$\begin{array}{l}\text { Counselling, refer to a physician if } \\
\text { required }\end{array}$} \\
\hline & $\begin{array}{l}\text { Ershadnagar, } \\
\text { Rangpur (HS-13) }\end{array}$ & & & \\
\hline & $\begin{array}{l}\text { New Jummapara } \\
\text { (HS-14) }\end{array}$ & & & \\
\hline
\end{tabular}


$\checkmark$ Sammanipur (HS-

15)

Sathmatha (HS-16)

\begin{tabular}{|c|c|c|c|c|}
\hline \multirow{3}{*}{$\begin{array}{l}\text { HS:17- } \\
18\end{array}$} & UHC (LID) & \multirow[t]{3}{*}{02} & \multirow[t]{3}{*}{$\mathrm{RMO} / \mathrm{MO}$} & \multirow[t]{3}{*}{ Treatment, referral, and follow-up } \\
\hline & $\begin{array}{l}\text { Taraganj UHC, } \\
\text { Rangpur (HS-17) }\end{array}$ & & & \\
\hline & $\begin{array}{l}\text { Ulipur UHC, } \\
\text { Rangpur (HS-18) }\end{array}$ & & & \\
\hline \multirow{3}{*}{$\begin{array}{l}\text { HS:19- } \\
20\end{array}$} & USC & \multirow[t]{3}{*}{02} & \multirow[t]{3}{*}{ SACMO } & \multirow[t]{3}{*}{ Counselling, referral } \\
\hline & $\begin{array}{l}\text { Kursha USC, } \\
\text { Taraganj, Rangpur } \\
\text { (HS-19) }\end{array}$ & & & \\
\hline & $\begin{array}{l}\text { Bozra USC, Ulipur, } \\
\text { Rangpur (HS-20) }\end{array}$ & & & \\
\hline \multirow{3}{*}{$\begin{array}{l}\text { HS-21- } \\
22\end{array}$} & $\mathrm{CC}$ & \multirow[t]{3}{*}{02} & \multirow[t]{3}{*}{$\mathrm{CHCP}$} & \multirow[t]{3}{*}{ Counselling, referral } \\
\hline & $\begin{array}{l}\text { South Kursha } \\
\text { Dangapara, Taraganj, } \\
\text { Rangpur (HS-21) }\end{array}$ & & & \\
\hline & $\begin{array}{l}\text { Kashiagari, Ulipur, } \\
\text { Rangpur (HS-22) }\end{array}$ & & & \\
\hline
\end{tabular}

Note: MO- Medical Officer, IMO-Indoor Medical Officer, RMO-Resident Medical Officer, SACMO- Sub Assistant Community Medical Officer, CHCP- Community Health Care Provider, UPHCC-Urban Primary Health Care Center, UHC-Upazila Health Complex, USC-Union Sub Center, CC-Community Clinic, HID- High Income Division, LID- Low Income Division.

Table 4: Characteristics of PHCCs in Bangladesh 


\begin{tabular}{|c|c|c|c|c|c|}
\hline PHCCs & $\begin{array}{l}\text { Number of } \\
\text { health staff }\end{array}$ & $\begin{array}{l}\text { Responsible } \\
\text { Ministry }\end{array}$ & $\begin{array}{l}\text { Staff } \\
\text { Working } \\
\text { hour }\end{array}$ & $\begin{array}{l}\text { Essential NCD medicine } \\
\text { and equipment } \\
\text { recommended by PEN }\end{array}$ & $\begin{array}{l}\text { Screening } \\
\text { available for } \\
\text { NCD }\end{array}$ \\
\hline $\begin{array}{l}\text { Urban } \\
\text { (HID } \\
\text { and } \\
\text { LID) }\end{array}$ & 16 & MoLG \& RD & 40hrs/week & Not all are available & $\begin{array}{l}\text { HTN, DM, } \\
\text { Breast cancer. }\end{array}$ \\
\hline \multicolumn{6}{|c|}{ Rural (HID and LID) } \\
\hline i) UHC & $\begin{array}{l}128 \text { (in } 50 \\
\text { bedded } \\
\text { facility), } \\
93 \text { (in } 31 \\
\text { bedded } \\
\text { facility) }\end{array}$ & $\mathrm{MOH} \& \mathrm{FW}$ & $\begin{array}{l}48 \mathrm{hrs} \\
\text { /week } \\
\text { (Shifting } \\
\text { duty) }\end{array}$ & $\begin{array}{l}\text { Almost all are available in } \\
\text { NCD pilot project UHCs }\end{array}$ & $\begin{array}{l}\text { HTN, DM, } \\
\text { breast and } \\
\text { cervical } \\
\text { cancer }\end{array}$ \\
\hline ii) USC & 04 & & $\begin{array}{l}39 \\
\text { hrs/week }\end{array}$ & No & HTN, DM \\
\hline iii) CC & $\begin{array}{l}\text { 01- } \\
\text { permanent } \\
\text { 02- part- } \\
\text { time }\end{array}$ & & $\begin{array}{l}36 \\
\text { hrs/week }\end{array}$ & No & HTN, DM \\
\hline
\end{tabular}

Note: MoLG \& RD- Ministry of Local Government and Rural Development, MOH \&FW- Ministry of Health and Family Welfare, UHC-Upazila Health Complex, USC-Union Sub Center, CC-Community Clinic, HID- High Income Division, LID- Low Income Division, HTN- Hypertension, DM-Diabetes Mellitus.

Table 5: Risk prediction tools for implementing essential NCD interventions in primary care- 


\begin{tabular}{|c|c|c|c|c|}
\hline \multirow[t]{2}{*}{ Tools } & \multicolumn{2}{|l|}{ Urban } & \multicolumn{2}{|l|}{ Rural } \\
\hline & Available & $\begin{array}{l}\text { Used by } \\
\text { professionals }\end{array}$ & Available & Used by professionals \\
\hline $\begin{array}{l}\text { WHO/ISH risk prediction } \\
\text { charts* }^{*}\end{array}$ & $\mathbf{x}$ & $\mathbf{x}$ & $\sqrt{ }$ & $\begin{array}{l}\sqrt{ } \text { (used only by Pilot } \\
\text { project UHC of LID) }\end{array}$ \\
\hline $\begin{array}{l}\text { Evidence based clinical } \\
\text { protocols }\end{array}$ & $\mathbf{x}$ & $\mathbf{x}$ & $\mathbf{x}$ & $\mathbf{x}$ \\
\hline $\begin{array}{l}\text { Flow charts with referral } \\
\text { criteria }\end{array}$ & $\mathbf{x}$ & $\mathbf{x}$ & $\sqrt{ }$ & $\begin{array}{l}\sqrt{ } \text { (used only by Pilot } \\
\text { project UHC of LID) }\end{array}$ \\
\hline Patient clinical record & $\mathbf{x}$ & $\mathbf{x}$ & $\mathbf{x}$ & $\mathbf{x}$ \\
\hline $\begin{array}{l}\text { Medical information } \\
\text { register }\end{array}$ & $\mathbf{x}$ & $\mathbf{x}$ & $\mathbf{x}$ & $\mathbf{x}$ \\
\hline $\begin{array}{l}\text { Audit tools (C and } \\
\text { standard) }\end{array}$ & $\mathbf{x}$ & $\mathbf{x}$ & $\mathbf{x}$ & $\mathbf{x}$ \\
\hline
\end{tabular}

*WHO/ISH risk prediction charts were translated into the local language (Bangla) and used for training the health workers PEN pilot UHCs of LID.

\section{Figures}




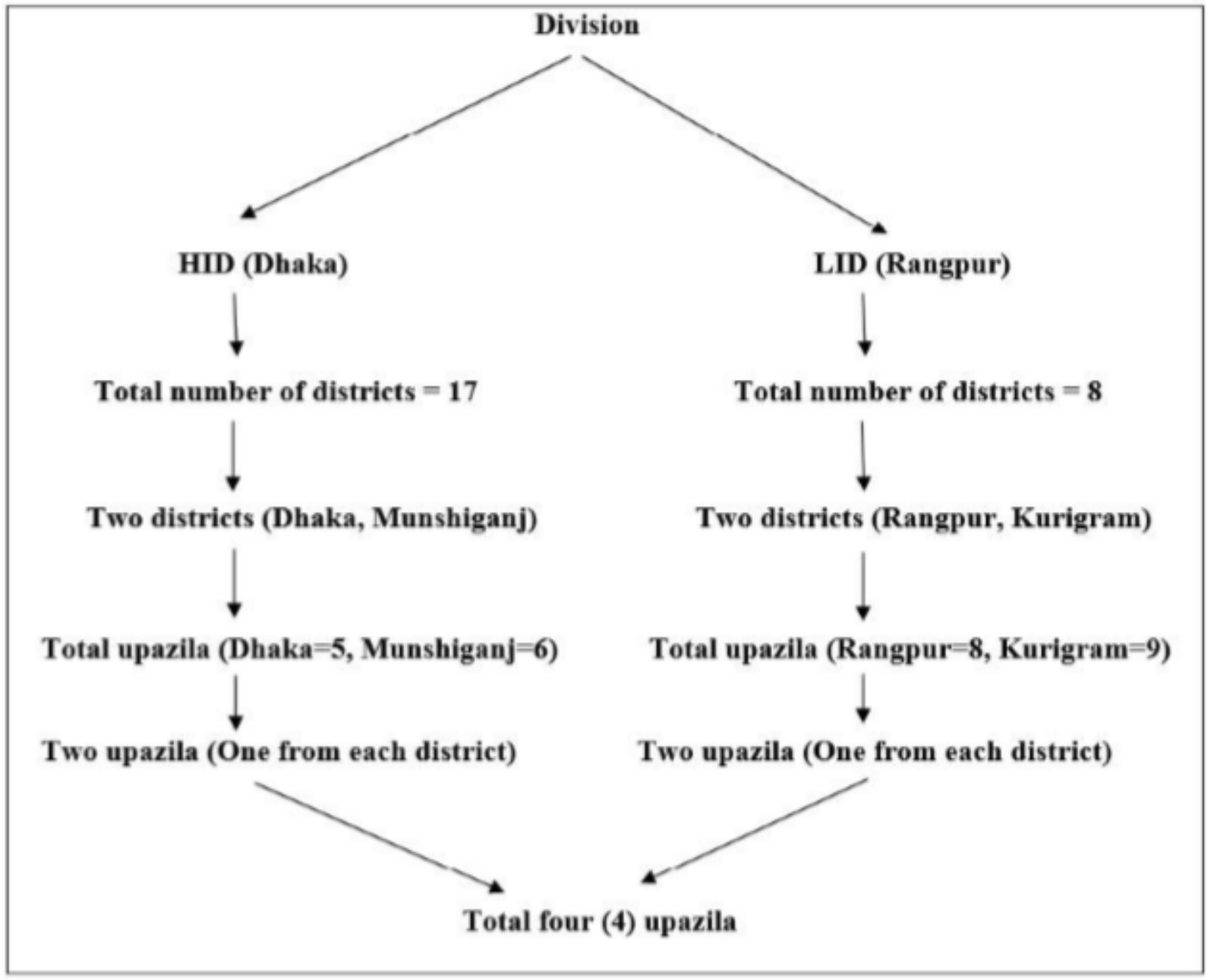

\section{Figure 1}

Flow chart describing the sampling strategy for PHCCs Note: HID-High Income Division; LID-Low Income Division; PHCC-Primary Health Care Center

\section{Supplementary Files}

This is a list of supplementary files associated with this preprint. Click to download.

- Additionalfile1.docx

- Additionalfile2.docx

- Additionalfile3COREQ.docx 